\title{
Comparison between POES energetic electron precipitation observations and riometer absorptions: Implications for determining true precipitation fluxes
}

\author{
Craig J. Rodger, ${ }^{1}$ Andrew J. Kavanagh, ${ }^{2}$ Mark A. Clilverd, ${ }^{2}$ and Steve R. Marple ${ }^{3}$ \\ Received 10 September 2013; revised 11 November 2013; accepted 13 November 2013; published 3 December 2013.
}

[1] Energetic electron precipitation (EEP) impacts the chemistry of the middle atmosphere with growing evidence of coupling to surface temperatures at high latitudes. To better understand this link, it is essential to have realistic observations to properly characterize precipitation and which can be incorporated into chemistry-climate models. The Polar-orbiting Operational Environmental Satellite (POES) detectors measure precipitating particles but only integral fluxes and only in a fraction of the bounce loss cone. Ground-based riometers respond to precipitation from the whole bounce loss cone; they measure the cosmic radio noise absorption (CNA), a qualitative proxy with scant direct information on the energy flux of EEP. POES observations should have a direct relationship with $\triangle \mathrm{CNA}$ and comparing the two will clarify their utility in studies of atmospheric change. We determined ionospheric changes produced by the EEP measured by the POES spacecraft in $\sim 250$ overpasses of an imaging riometer in northern Finland. The $\triangle \mathrm{CNA}$ modeled from the POES data is $10-15$ times less than the observed $\triangle \mathrm{CNA}$ when the $>30 \mathrm{keV}$ flux is reported as $<10^{6} \mathrm{~cm}^{-2} \mathrm{~s}^{-1} \mathrm{sr}^{-1}$. Above this level, there is relatively good agreement between the space-based and ground-based measurements. The discrepancy occurs mostly during periods of low geomagnetic activity, and we contend that weak diffusion is dominating the pitch angle scattering into the bounce loss cone at these times. A correction to the calculation using measurements of the trapped flux considerably reduces the discrepancy and provides further support to our hypothesis that weak diffusion leads to underestimates of the EEP.

Citation: Rodger, C. J., A. J. Kavanagh, M. A. Clilverd, and S. R. Marple (2013), Comparison between POES energetic electron precipitation observations and riometer absorptions: Implications for determining true precipitation fluxes, J. Geophys. Res. Space Physics, 118, 7810-7821, doi:10.1002/2013JA019439.

\section{Introduction}

[2] The coupling of the Van Allen radiation belts to the Earth's atmosphere through precipitating particles is an area of intense scientific interest, principally due to two separate research activities. One of these concerns the physics of the radiation belts and primarily the evolution of energetic electron fluxes during and after geomagnetic storms [e.g., Reeves et al., 2003] where precipitation losses in to the atmosphere play a major role [Green et al., 2004; Millan and Thorne, 2007]. The other focuses on the response of the atmosphere to precipitating particles, with a possible linkage to polar climate variability [e.g., Turunen et al., 2009; Seppälä et al., 2009].

[3] Precipitating charged particles produce odd nitrogen and odd hydrogen in the Earth's atmosphere which can

\footnotetext{
${ }^{1}$ Department of Physics, University of Otago, Dunedin, New Zealand.

${ }^{2}$ British Antarctic Survey (NERC), Cambridge, UK.

${ }^{3}$ Department of Physics, Lancaster University, Lancaster, UK.

Corresponding author: C. J. Rodger, Department of Physics, University of Otago, PO Box 56, Dunedin 9016, New Zealand. (crodger@physics.otago.ac.nz)

(C)2013. American Geophysical Union. All Rights Reserved. 2169-9380/13/10.1002/2013JA019439
}

catalytically destroy ozone [Brasseur and Solomon, 2005]. For some time, it has been recognized that very intense energetic particle precipitation (EPP) events could lead to significant ozone destruction in the polar middle atmosphere, which was subsequently experimentally observed during solar proton events [e.g., Seppälä et al., 2006, 2007]. However, there has also been growing evidence that both geomagnetic storms and substorms produce high levels of energetic electron precipitation [e.g., Rodger et al., 2007; Clilverd et al., 2008, 2012], with modeling suggesting energetic electron precipitation (EEP) can also lead to significant mesospheric chemical changes in the polar regions [Rodger et al., 2010c]. The latter study concluded that the chemical changes could occur with an intensity similar to that of a mediumsized solar proton event. In support of this, recent experimental studies have demonstrated the direct production of odd nitrogen [Newnham et al., 2011] and odd hydrogen [Verronen et al., 2011; Andersson et al., 2012, 2013] in the mesosphere by EEP, along with ozone decreases [Daae et al., 2012]. In particular, Andersson et al. [2012] reported experimental evidence of electron precipitation produced odd hydrogen changes stretching over the altitude range from $\sim 52$ to $82 \mathrm{~km}$ (corresponding to electrons from $\sim 100 \mathrm{keV}$ to $\sim 3 \mathrm{MeV}$ ), while Daae et al. [2012] observed a decrease of 
Table 1. An Overview of the Five Satellites That Carry the SEM-2 Instrument Package and Are Used in Our Study ${ }^{\mathrm{a}}$

\begin{tabular}{lccc}
\hline Satellite & $\begin{array}{c}\text { Local Time } \\
\text { Ascending Node }\end{array}$ & Altitude $(\mathrm{km})$ & Data Availability \\
\hline NOAA 15 & $16: 42: 14$ & 807 & 1 June 1998 \\
NOAA 16 & $20: 28: 56$ & 849 & 10 January 2001 \\
NOAA 17 & $19: 12: 50$ & 810 & 12 July 2002 \\
NOAA 18 & $14: 51: 13$ & 854 & 7 June 2005 \\
MetOp-02 & $21: 30: 22$ & 817 & 3 December 2006 \\
\hline
\end{tabular}

${ }^{\mathrm{a}}$ The table includes their daytime orbital sector and date at which they became operational. Note MetOp-02 is a European spacecraft but carries the same SEM-2 package as the NOAA spacecraft. The local time ascending node is the local time for which the spacecraft are crossing the equator traveling northward.

$20-70 \%$ in the mesospheric ozone immediately following a moderate geomagnetic storm $(K p \approx 6)$.

[4] There has also been evidence that the effects of energetic particle precipitation may couple into surface climate at high latitudes. Rozanov et al. [2005] and Baumgaertner et al. [2011] imposed a $\mathrm{NO}_{x}$ source to represent the EEP linkage into their chemistry-climate model and found large $( \pm 2 \mathrm{~K})$ variations in polar surface air temperatures. They concluded that the magnitude of the atmospheric response to EEP events could potentially exceed the effects from solar UV fluxes. This conclusion was tested using the experimentally derived ERA-40 and European Centre for MediumRange Weather Forecasts operational surface level air temperature data sets to examine polar temperature variations during years with different levels of geomagnetic activity [Seppälä et al., 2009]. The latter authors found that surface level air temperatures could differ by as much as $\pm 4.5 \mathrm{~K}$ between high and low geomagnetic storm periods but that these changes were not linked to changing solar irradiance/EUV levels. The Seppälä et al. [2009] study argues that the seasonality and temporal offsets observed strongly suggest that the dominant driver for this temperature variability comes from EEP coupling to ozone through $\mathrm{NO}_{x}$ production. Very recently, additional analysis has shed light on the link between EEP, EPP-generated $\mathrm{NO}_{x}$, and stratospheric dynamics [Seppälä et al., 2013]. This study concluded EEP-generated $\mathrm{NO}_{x}$ alters planetary wave breaking in the lower stratosphere, leading to more planetary waves propagating into the lowlatitude upper stratosphere, which then results in the dynamical responses seen later during the winter.

[5] A key component in understanding the link between EEP and atmospheric changes in experimental data is experimental observations of energetic electron precipitation. Further studies making use of chemistry climate models also require realistic EEP observations or some sort of proxy representations of EEP in order to characterize the effects.

[6] Unfortunately, there are very little experimental observations which can fill this role. The majority of scientific and operational spacecraft measuring energetic electron fluxes in the radiation belts report only the total trapped fluxes, as they do not have sufficient angular resolution to resolve the pitch angles of the bounce loss cone (BLC). This will also be true of the recently launched Van Allen Probes. Scientific studies on energetic electron losses to date have tended to focus on observations from the Solar Anomalous and Magnetospheric Particle Explorer (SAMPEX) or Polar-orbiting Operational Environmental Satellites (POES) spacecraft, both of which have significant weaknesses. In the case of SAMPEX, the measurements are primarily of the drift loss cone (DLC) rather than the BLC [Dietrich et al., 2010] and are largely limited to an integral electron flux value above $\sim 1 \mathrm{MeV}$. The Medium Energy Proton and Electron Detector (MEPED) in the Space Environment Monitor-2 (SEM-2) instrument carried onboard POES is unusual in that it includes a telescope which views some fraction of the bounce loss cone [Rodger et al., 2010b] but is limited by measuring only three integral energy ranges $(>30,>100$, and $>300 \mathrm{keV})$, while also suffering from significant contamination by low-energy protons [Rodger et al., 2010a]. Recent studies have suggested that the POES EEP measurements may underestimate the true fluxes striking the atmosphere. Comparisons between ground-based observations and average MEPED/POES EEP measurements lead to EEP flux magnitudes which differ by factors ranging from 1 to 100, depending on the study [e.g., Clilverd et al., 2012; Hendry et al., 2013; Clilverd et al., 2013]. These studies have suggested that the MEPED/POES electron detectors give a good idea of the variation in precipitation levels but suffer from large uncertainties in their measurement of flux levels. In contrast, other studies are relying upon MEPED/POES precipitation measurements to feed chemistry-climate models. One example of this is the Atmospheric Ionization Module Osnabrück (AIMOS) model which combines experimental observations from low Earth orbiting POES spacecraft along with geostationary measurements and with geomagnetic observations to provide 3-D numerical model of atmospheric ionization [Wissing and Kallenrode, 2009]. AIMOS outputs during solar proton event (SPE) and geomagnetic storms have been used to draw conclusions as to the relative significance of such events to the middle atmosphere [e.g., Funke et al., 2011], and a validation of AIMOS outputs for altitudes $>100 \mathrm{~km}$ altitude has been undertaken [Wissing et al., 2011].

[7] In order to make best use of MEPED/POES EEP measurements, it is necessary to better understand these measurements and how they compare with experimental observations of the impact of the EEP upon the middle atmosphere and lower ionosphere. In this paper we examine MEPED/POES EEP measurements during satellite overflights of a riometer located in Kilpisjärvi, Finland. As the riometer responds to EEP by measuring the ionospheric changes produced by the EEP, there should be a direct relationship between the EEP observations and the riometer absorption changes. We use modeling to link the two, fitting the integral flux channels with a power law and determining the change in electron density profile that would then arise in the lower ionosphere. A direct comparison can then be made between the riometer response predicted by the satellite EEP observations and the experimentally observed riometer absorptions. Our goal in this study is to test the accuracy of the MEPED/POES satellite EEP measurements, as well as providing better understanding of the mechanisms driving EEP.

\section{Data Descriptions}

\subsection{POES Satellite SEM-2 Data}

[8] The second generation Space Environment Module-2 (SEM-2) [Evans and Greer, 2004] is flown on the Polar Orbiting Environmental Satellites (POES) series of satellites and on the meteorological operational (MetOp)-02 spacecraft. Table 1 contains a summary of the SEM-2 carrying 


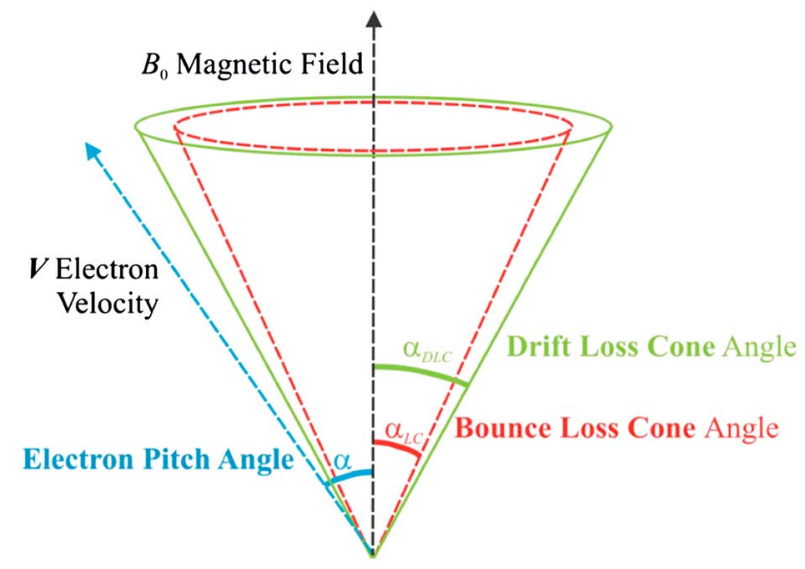

Figure 1. Schematic of the atmospheric loss cones. The Electron pitch angle, $\alpha$, is defined by the angle between the electron velocity vector and the magnetic field line. The angular width of the local bounce loss cone, $\alpha_{\mathrm{BLC}}$, is determined by the pitch angle of particles on this field line which will mirror inside the atmosphere (at $\sim 100 \mathrm{~km}$ ). The drift loss cone width, $\alpha_{\mathrm{DLC}}$, is determined by the largest $\alpha_{\mathrm{BLC}}$ for that drift shell.

spacecraft operational during our study period, which spans from mid-1998 when NOAA-15 starts to provide scientific observations through to the end of 2008. These spacecraft are in Sun-synchronous polar orbits with typical parameters of $\sim 800-850 \mathrm{~km}$ altitude, $102 \mathrm{~min}$ orbital period, and $98.7^{\circ}$ inclination [Robel, 2009]. The orbits typically are either morning or afternoon daytime equator crossings, with corresponding nighttime crossings.

[9] In this study we use SEM-2 Medium Energy Proton and Electron Detector (MEPED) observations. The SEM-2 detectors include integral electron telescopes with energies of $>30 \mathrm{keV}(\mathrm{e} 1),>100 \mathrm{keV}(\mathrm{e} 2)$, and $>300 \mathrm{keV}$ (e3), pointed in two directions. In this study we focus primarily upon the $0^{\circ}$ pointing detectors. The telescopes are $\pm 15^{\circ}$ wide. Modeling work has established that the $0^{\circ}$ telescope monitor particles in the atmospheric bounce loss cone that will enter the Earth's atmosphere below the satellite when the spacecraft is poleward of $L \approx 1.5-1.6$, while the $90^{\circ}$ telescope monitors trapped fluxes or those in the drift loss cone, depending primarily upon the $L$ shell [Rodger et al., 2010b, Appendix A].

[10] Rodger et al. [2010a] found that as much as $\sim 42 \%$ of the $0^{\circ}$ telescope $>30 \mathrm{keV}$ electron observations from MEPED were contaminated by protons in the energy range $\sim 100 \mathrm{keV}-3 \mathrm{MeV}$ [Yando et al., 2011] although the situation was less marked for the $90^{\circ}$ telescope $(3.5 \%)$. However, NOAA has developed new techniques to remove this proton contamination as described in Lam et al. [2010, Appendix A]. This algorithm is available for download through the Virtual Radiation Belt Observatory (http://virbo.org) and has been applied to all of the data in our study. This algorithm does not work for solar proton events as we will discuss later.

\subsection{Viewing the Bounce Loss Cone}

[11] Before discussing the criteria for data selection, we briefly summarize some relevant features concerning pitch angles in the radiation belts; more detailed descriptions may be found elsewhere [e.g., Walt, 1984; Spjeldvik and
Rothwell, 1985]. The pitch angle $(\alpha)$ of a charged particle in the radiation belts is defined by the angle between the particle velocity vector and the magnetic field line. While the pitch angle changes along the magnetic field line, a locally trapped particle has a pitch angle of $90^{\circ}$. Particles trapped in the radiation belts have a range of pitch angle at the geomagnetic equator from $90^{\circ}$ down to the bounce loss cone angle, $\left(\alpha_{\mathrm{BLC}}\right)$, and pitch angles are generally referenced to the geomagnetic equator. Any particle whose pitch is smaller than $\alpha_{\mathrm{BLC}}$ will mirror at altitudes below $\sim 100 \mathrm{~km}$, inside the Earth's atmosphere, and thus have a high probability of encountering an atmospheric molecule and being lost through precipitation. In practice, a particle whose pitch angle lies inside the BLC will precipitate out within a small number of bounces.

[12] The angular width of the BLC is dependent on the geomagnetic field strength at $\sim 100 \mathrm{~km}$, which varies across the Earth. Thus, $\alpha_{\mathrm{BLC}}$ will vary locally as the particle drifts around the Earth (eastward for electrons and westward for protons). A radiation belt particle will experience the lowest field strengths and thus the largest local $\alpha_{\mathrm{BLC}}$, around the Antarctic Peninsula and Weddell Sea (for the inner radiation belt), and south of the Antarctic Peninsula (for the outer radiation belt). The local BLC with the largest angular width establishes the drift loss cone (DLC), which has angular width of $\alpha_{\text {DLC }}$ in pitch angle space. Figure 1 shows a schematic of the loss cones in pitch angle space, including an electron which has a pitch angle located outside of the DLC and thus will be mirroring above the atmosphere. A particle with a pitch angle lying between $\alpha_{\mathrm{DLC}}$ and $\alpha_{\mathrm{BLC}}$ (i.e., $\alpha_{\mathrm{BLC}}<\alpha<\alpha_{\mathrm{DLC}}$ ) will drift around the world mirroring just above the atmosphere until reaching the same longitudes as the South American Magnetic Anomaly (SAMA), at which point the local $\alpha_{\mathrm{BLC}}$ grows until $\alpha_{\mathrm{BLC}}>\alpha$ and the particle precipitates. Examples of this can be seen in the scattering of inner belt electrons into the DLC by a ground-based VLF transmitter [e.g., Gamble et al., 2008, Figure 5; Rodger et al., 2010b, Figure 6]. Recent evidence has been put forward showing that there are increased atmospheric $\mathrm{HO}_{x}$ concentrations for the locations where the particles in the DLC precipitate into the atmosphere [Andersson et al., 2013]. To fully characterize the loss of radiation belt electrons into the atmosphere would require an instrument capable of unambiguously resolving the BLC and thereby determining the full flux of precipitating electrons. Such a measurement is not currently available, the best we have is the $0^{\circ}$ MEPED telescope, but this data clearly have limitations as we will explore.

[13] For the vast majority of locations relevant to precipitation from the radiation belts, substorms or solar proton events, the $0^{\circ}$ MEPED telescope only views particles with pitch angles inside the BLC [Rodger et al., 2010b, Figure A3]. However, at POES altitudes, $\alpha_{\mathrm{BLC}}$ is significantly larger than the $\pm 15^{\circ}$ telescope width, such that the $0^{\circ}$ telescope only observes a fraction of the bounce loss cone. Figure 2 provides an estimate of how this varies across the globe, building on the Rodger et al. [2010b, Appendix A] modeling. For large portions of the Earth, only $40-50 \%$ of the BLC radius is viewed, decreasing to zero near the geomagnetic equator where the $0^{\circ}$ telescope would view locally trapped particles (should such a population exist). The fraction of the BLC viewed by the $0^{\circ}$ telescope is shown for two specific locations in Figure 3. This shows the situation for the magnetic field line which starts $100 \mathrm{~km}$ in altitude above the 


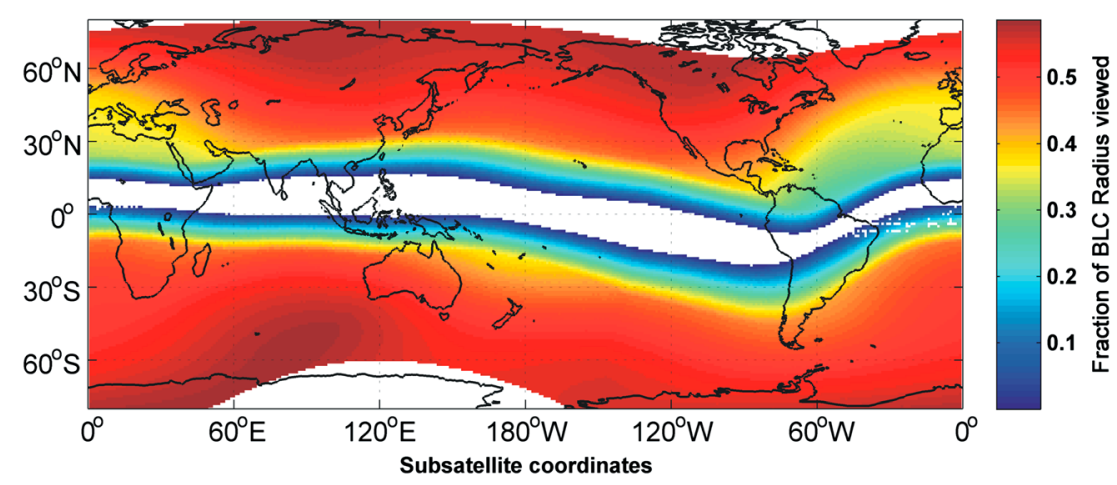

Figure 2. World map showing the ratio of the $0^{\circ}$ telescope viewing field $\left( \pm 15^{\circ}\right.$ telescope at POES satellite altitudes) to the bounce loss cone angle, $\alpha_{\mathrm{BLC}}$.

Kilpisjärvi riometer facility $\left(69.05^{\circ} \mathrm{N}, 20.79^{\circ} \mathrm{E}\right.$, International Geomagnetic Reference Field (IGRF) $L=6.13$; left) and for comparison the Antarctic station Halley $\left(75.5^{\circ} \mathrm{S},-26.9^{\circ} \mathrm{E}\right.$, IGRF $L=4.3$; right). In this plot, the centered cross represents the magnetic field line, while the dotted black line shows the viewing window the $\pm 15^{\circ}$ wide $0^{\circ}$ MEPED electron telescope, transformed to the geomagnetic equator. The equatorial pitch angle for the center of the $0^{\circ}$ telescope is shown by a circled cross. The angular size of the BLC is shown by the heavy black line, while the angular size of the DLC is shown by the light grey line. Note that for Kilpisjärvi, the DLC is essentially the same size as the BLC and hence is not visible. In the case of Kilpisjärvi, the $0^{\circ}$ MEPED electron telescope will sample $52 \%$ of the radial pitch angle range, and $\sim 7 \%$ of the BLC area, while for the contrasting case of Halley, the telescope samples $57 \%$ of the radial range and $\sim 7.5 \%$ of the BLC area.

[14] Basic radiation belt physics suggests that the fluxes in the BLC will exhibit circular symmetry and that the flux in the BLC may not be constant with pitch angle; one would often expect considerably more flux near the $\alpha_{\mathrm{BLC}}$ rather than near the center of the loss cone. In the common case where pitch angle scattering involves smaller changes toward
$\alpha_{\mathrm{BLC}}$, described as "weak diffusion," there are likely to be large differences between the edge and center of the BLC. Therefore, the $0^{\circ}$ telescope (as seen in Figure 2) could be failing to view a considerable amount of the flux in the BLC, and in this study we seek to test the importance of this issue. In practice, MEPED/POES electron telescope observations are converted from counts to flux through a geometric conversion factor [Evans and Greer, 2004; Yando et al., 2011] which takes into account the angular size of the telescope, as well as its sensitivity. This converts the counts measured by the telescope into an isotropic flux fully filling the BLC.

\subsection{Contamination by High Proton Fluxes}

[15] During solar proton events, large fluxes of high-energy protons $(>5 \mathrm{MeV})$ gain direct access to the geomagnetic field; the NOAA correction algorithm does not work at these times resulting in the appearance of large unphysical electron fluxes deep in the polar cap. We therefore remove all measurements at times when the MEPED P7 omnidirectional observations of $>36 \mathrm{MeV}$ protons reports $>3$ counts/s. We find this adequately removes the contamination caused by SPE. Figure 4 shows examples of the typical (median) $>100 \mathrm{keV}$ precipitating flux maps for the time period 1 January 2004 to 31
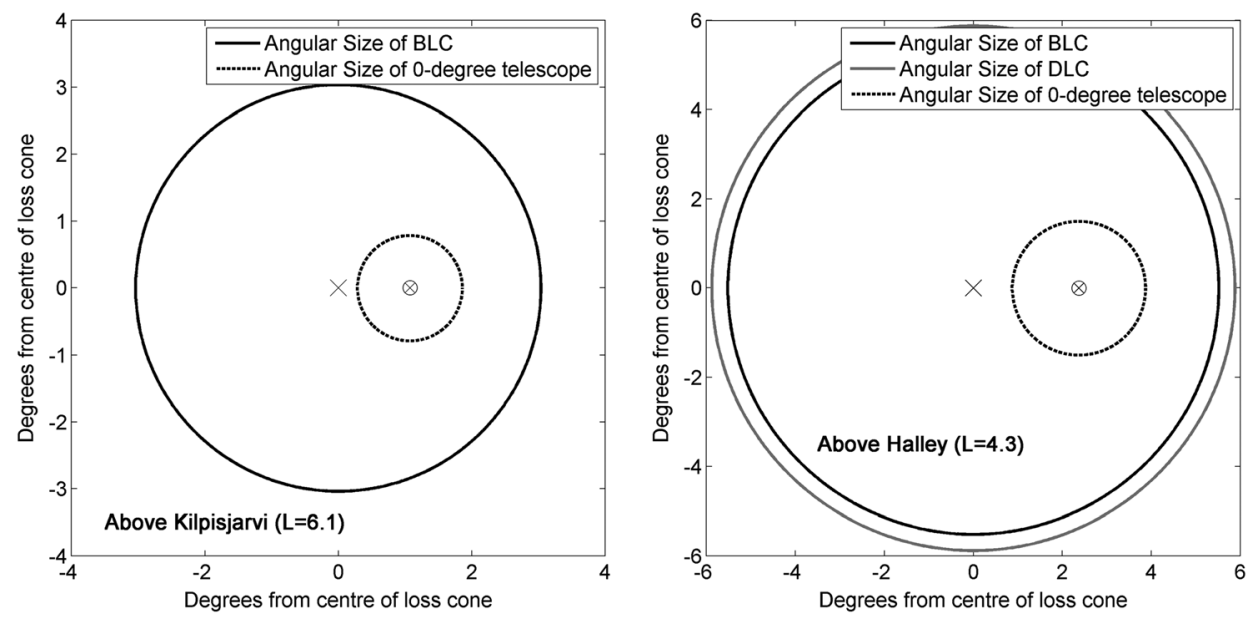

Figure 3. Examples of the loss cones viewed by the MEPED $0^{\circ}$ telescope above Kilpisjärvi and Halley station, shown at the geomagnetic equator. Note that the drift loss cone (DLC) is essentially the same as the bounce loss cone (BLC) at the top of the Kilpisjärvi field line, while there is a clear difference in the Halley case. The large cross represents the magnetic field line, while the circled cross represents the equatorial pitch angle for the center of the $0^{\circ}$ telescope. 

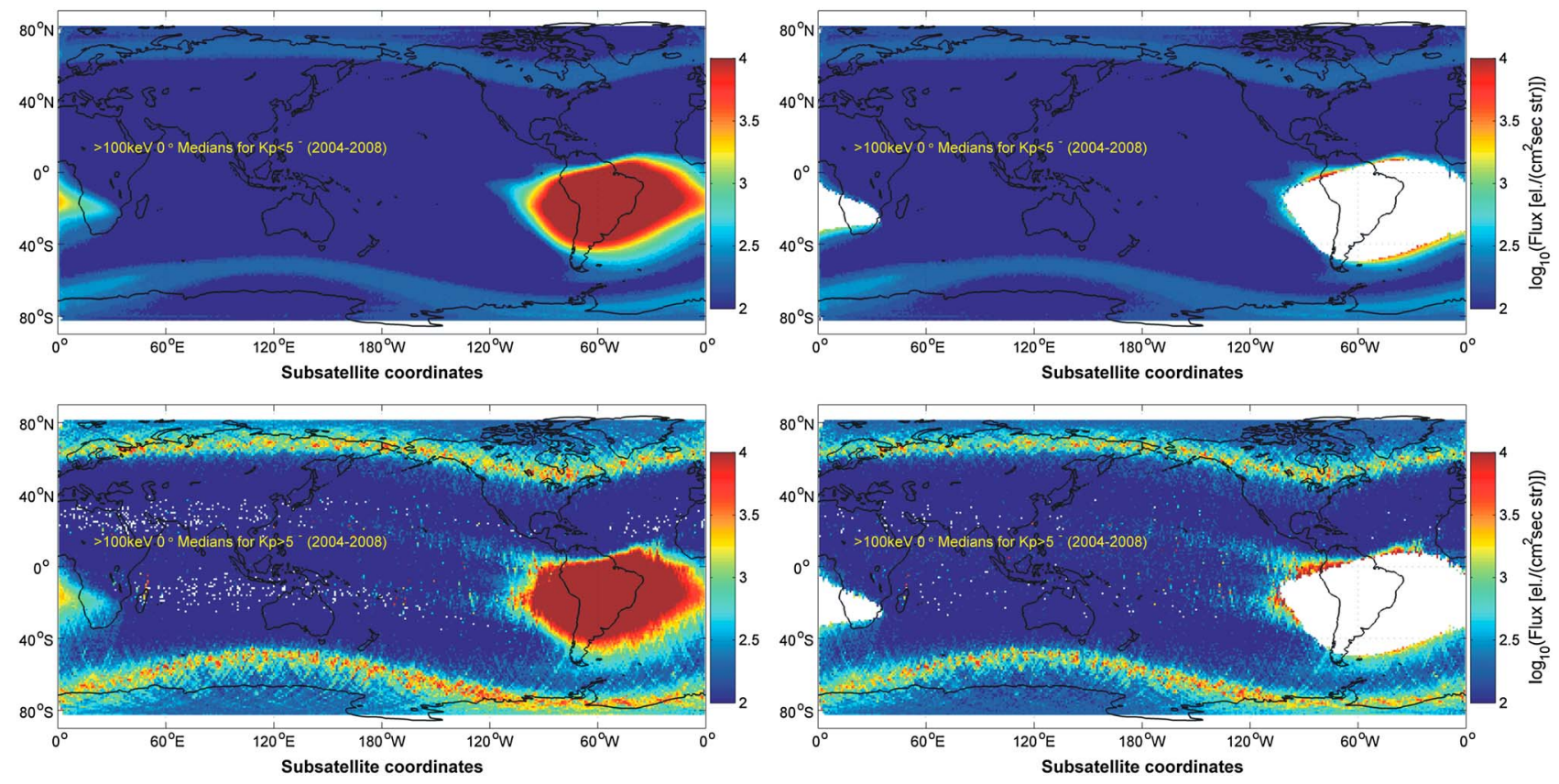

Figure 4. The global variation in median $>100 \mathrm{keV}$ electron precipitation reported by the POES spacecraft for the period spanning 1 January 2005 to 13 December 2006. (top row) The situation for quiet and moderately disturbed geomagnetic conditions (i.e., $K p \leq 5^{-}$); (bottom row) Storm times (i.e., $K p>5^{-}$). An additional proton contamination check is included for Figure 4 (right column) as outlined in the text, removing most of the SAMA (South Atlantic Magnetic Anomaly).

December 2008. Figure 4 (top row) is for quiet and moderately disturbed geomagnetic conditions (taken as when $K p \leq 5^{-}$), while Figure 4 (bottom row) is for geomagnetic storm conditions (taken as when $K p>5^{-}$). In this figure, Figure 4 (left column) shows the median fluxes when the P7 threshold is not applied, while Figure 4 (right column) is after the threshold. The very large values above the SAMA are totally removed, indicating the extremely large precipitating electron fluxes reported in this region are unreal and most likely caused by inner belt protons. Further support for this has recently been put forward from atmospheric $\mathrm{HO}_{x}$ observations [Andersson et al., 2013]. While the footprint of the outer radiation belt was visible in the atmospheric $\mathrm{HO}_{x}$ concentrations (and in particular the signature of the DLC), there was no $\mathrm{HO}_{x}$ signature in the SAMA, confirming both that the $0^{\circ}$ fluxes are incorrect in that region and also that there is very low precipitation.

[16] During quiet geomagnetic conditions (Figure 4, top row), precipitation can occur from the outer radiation belts in any longitude. However, it is enhanced in the longitudes of the Antarctic Peninsula and south of Africa, where electrons in the DLC precipitate into the atmosphere. This signature is not seen for geomagnetic storm conditions (Figure 4, bottom row), where all longitudes experience essentially the same precipitation from the radiation belts. Similar results were reported earlier by Horne et al. [2009], who showed a similar map for $>300 \mathrm{keV}$ precipitating electrons during the main phase of storms. That study argued that the storm time behavior of these electrons indicated "strong diffusion" [Kennel and Petschek, 1966; Baker et al., 1979] was taking place, where pitch angle scattering is strong enough to scatter electrons into the bounce loss cone and cause precipitation at any longitude. In contrast, Figure 4 (top row) is more consistent with weak diffusion occurring, where the electrons are mainly scattered into the drift loss cone and drift around the Earth to the longitudes of the Antarctic Peninsula where they are lost to the atmosphere.

\subsection{Kilpisjärvi Riometer Data}

[17] We will compare the $0^{\circ}$ telescope electron observations with riometer absorption observations from the IRIS (Imaging Riometer for Ionospheric Studies) instrument in Kilpisjärvi, Finland $\left(69.05^{\circ} \mathrm{N}, 20.79^{\circ} \mathrm{E}\right.$, IGRF $L=6.13$, Figure 5) [Browne et al., 1995]. Riometers (relative ionospheric opacity meter) utilize the absorption of cosmic radio noise by the ionosphere [Little and Leinbach, 1959] to measure the enhancement of $D$ region electron concentration caused by EEP. The riometer technique compares the strength of the cosmic radio noise signal received on the ground to the normal sidereal variation referred to as the absorption quiet day curve (QDC) to produce the change in cosmic noise absorption ( $\triangle \mathrm{CNA}$ ) above the background level. The cosmic radio noise propagates through the ionosphere, and part of the energy is absorbed due to the collision of the free ionospheric electrons with neutral atmospheric atoms.

[18] The Kilpisjärvi IRIS is a 64 antenna, 49 beam configuration [Detrick and Rosenberg, 1990], that records the $X$-mode cosmic radio noise at $38.2 \mathrm{MHz}$. The central beam (labeled as beam 25) of the array has a width of $11.17^{\circ}$; the beam width increases to a maximum of $13.89^{\circ}$ for beams at the edge of the array, and the wide beam has a width of $\sim 90^{\circ}$. The field of view encompasses $5^{\circ}\left(3^{\circ}\right)$ longitude and $2^{\circ}\left(1.5^{\circ}\right)$ latitude in geographic (geomagnetic) coordinates. All of the beams are sampled every second, recording the cosmic radio noise at $38.2 \mathrm{MHz}$. QDC for IRIS 


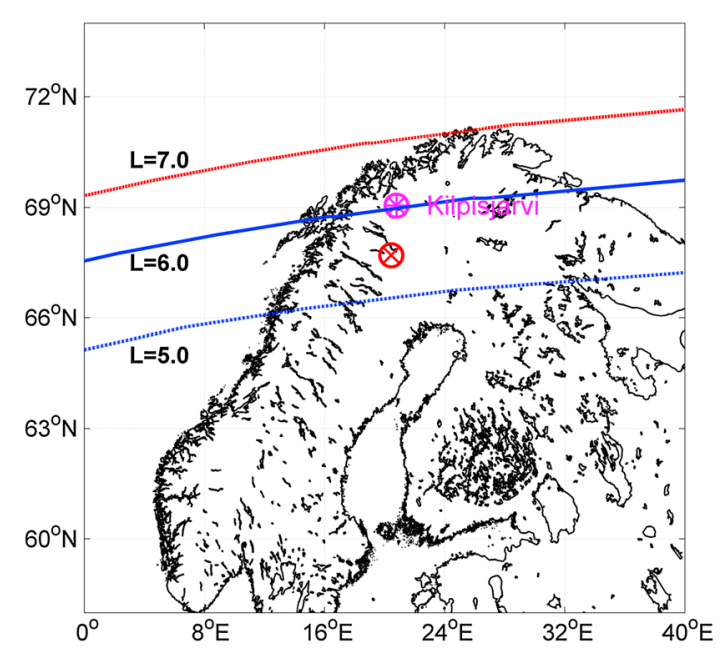

Figure 5. Map showing the location of the Kilpisjärvi riometer (magenta star) and the POES subsatellite location whose footprint at $100 \mathrm{~km}$ altitude is located above the riometer (red cross). A set of IGRF $L$ shell contours at $100 \mathrm{~km}$ are also marked.

are derived from the data using an advanced variant of the percentile method described in Browne et al. [1995]. At least 16 days of contiguous data (covering the desired period of observation and enough days to ensure a quiet period) are smoothed using a median filter (of length $599 \mathrm{~s}$ ). The data are then binned according to sidereal time and sorted in descending order. Next, the mean of the $m$ th to $n$th highest values are taken: For geomagnetically quiet times, when there are many quiet days, typical values are $m=4$ and $n=5$; for more active periods, with fewer quiet days, typical values are $m=2$ and $n=3$. These mean values provide the basis for the QDC, which is further smoothed with a truncated Fourier series and filtered via Fourier transform to remove high-frequency components. Deriving the QDC in this manner removes CNA from solar ionization (such that $\triangle \mathrm{CNA}$ is references to "zero" for IRIS) and limits system specific effects (such as antenna deterioration and snow accumulation at the site). Filtering techniques are applied to the data prior to QDC formation to remove the effects of solar radio emission and scintillation from radio stars. The former can lead to underestimates of the $\triangle \mathrm{CNA}$ since the received power is boosted above the level we would expect from the radio sky [Kavanagh et al., 2004b] when the Sun is in the beam or a major side lobe of the riometer. The QDC will always have some small uncertainty in how well they represent the "zero" line, but all curves for this study have been visually inspected. It is the availability of this long data set of carefully checked $\triangle$ CNA observations which caused us to focus upon the Kilpisjärvi IRIS for the current study, rather than other similar systems located around the world.

[19] The resultant $\triangle \mathrm{CNA}$ is primarily a measure of EEP, being sensitive to electron number density changes in the $D$ layer of the ionosphere. There have been attempts to link $\triangle \mathrm{CNA}$ to fluxes of electrons using simple models [e.g., Collis et al., 1984] and some success at using overlapping imaging riometers to determine the height of the absorbing layer and hence the responsible energy [e.g., Wild et al.,
2010]. The riometer has the potential to be an important ground truth for satellite studies since it is sensitive to all of the precipitating electrons with energy $>30 \mathrm{keV}$.

\section{Data Selection}

[20] IRIS data have been recorded continuously since September 1994 at $1 \mathrm{~s}$ cadence (in practice, limited data gaps occur due to technical faults at the riometer site). In this study we use 1 min means around the time the satellite passes the $L$ shell of the riometer but only use a "minute" interval if there are at least $20 \mathrm{~s}$ of valid observations within the minute of the satellite pass. If the absorption is negative, we assume the QDC is not well fitted and discard the data. The magenta star in Figure 5 shows the location of the riometer. As the EEP will follow the field line until striking the atmosphere, we do not take POES observations directly above the riometer. The red cross in Figure 5 shows the subsatellite location for a fieldline at POES altitudes which is traced down the geomagnetic field to the atmosphere above Kilpisjärvi using IGRF. Conjunctions between IRIS and POES are identified as when the satellite passes within $\pm 3^{\circ}$ in latitude and $\pm 10^{\circ}$ in longitude of the Kilpisjärvi riometer (taking into account the need to correct for fieldline tracing). As an extreme limit, we require at least two $1 \mathrm{~s}$ MEPED/POES observations in a single overpass to include data from that overpass, and typically, there are between 10 and $111 \mathrm{~s}$ samples included in each overpass.

[21] For this study, we use the three precipitating electron channels of MEPED/POES (e1, e2, and e3 channels) fitted to a power law using least squares fitting, and we require that the fitted power law is within $\pm 50 \%$ of the observed $>30 \mathrm{keV}$ precipitating electron flux for the fit to be regarded as valid. A further constraint is the noise floor of the MEPED/POES electron observations, which is a flux of 100 electrons $\mathrm{cm}^{-2} \mathrm{~s}^{-1} \mathrm{sr}^{-1}$; consequently, we remove any passes where this constraint is breached.

[22] A riometer is sensitive to any process that changes the electron number density in the lower ionosphere such as solar proton precipitation or X-ray impact from solar flares. The latter are excluded by limiting observations to nightside periods where the solar zenith angle $>120^{\circ}$. This also removes contamination of the riometer signal by solar radio emission; Kavanagh et al. [2004a, 2004b] showed that radio bursts can lead to underestimates of CNA and in the most severe cases will produce negative $\triangle \mathrm{CNA}$ values by increasing the received signal above the natural QDC level. Characterizing and correcting for this problem is not a simple process [Kavanagh et al., 2012]. We remove the effect of solar proton events using the 8.7-14.5 MeV proton observations from GOES; when the flux in this energy range is $\geq 0.75$ counts $\mathrm{cm}^{-2} \mathrm{~s}^{-1} \mathrm{sr}^{-1} \mathrm{MeV}^{-1}$, we exclude that time period. As stated earlier, the MEPED/POES instrument detects protons [e.g., Neal et al., 2013]; however, it is less sensitive than those made by GOES such that small events which are observable in ground-based ionospheric data [Clilverd et al., 2006] are not visible in MEPED/POES data and also do not meet the "standard definition" of a solar proton event determined using GOES data as they are too "weak."

[23] From the original Kilpisjärvi 1 min data set spanning $1995-2008,27.5 \%$ of the data is removed from the data quality tests and an additional $3 \%$ by the POES proton 
thresholding. The requirement that the ionosphere above Kilpisjärvi is not sunlit is considerably more prescriptive, and after this is enforced, $92.6 \%$ of the data has been removed, leaving $7.4 \%$ of the total data set which is of good quality, unaffected by solar protons and for a nighttime ionosphere. This is equal to 380.0 days of 1 min observations (547,255 samples). By observing the additional criteria outlined above, and in particular the requirement for a spatially close overpass, we are left with a maximum of 254 conjunctions between 1 June 1998 and 31 December 2008, with acceptable data from both MEPED/POES and IRIS. Due to the listed constraints, there are 254 median EEP values and 243 mean EEP values that can be used for comparison.

\section{Modeling of Electron Density Produced Ionization Changes}

\subsection{EEP Produced Changes in Electron Number Density}

[24] In order to estimate the response of the riometer data to EEP, we follow the calculation approach outlined by Rodger et al. [2012]. This approach allows one to use POES EEP observations to determine riometer absorption, by determining the changing ionospheric electron number density and hence calculating the changing radio wave absorption. We determine the change in ionospheric electron number density over the altitude range $40-150 \mathrm{~km}$ caused by precipitation assuming EEP spanning the energy range $10 \mathrm{keV}-3 \mathrm{MeV}$. The ambient, or undisturbed electron density profile, is provided by the International Reference Ionosphere (IRI-2007) (online from http://omniweb.gsfc.nasa.gov/vitmo/iri_vitmo.html) for 16 January at 23.5 UT for night conditions, with the "STORM" model switched off. As the IRI does not include all of the $D$ region, particularly during the nighttime, we combine the IRI results with typical $D$ region electron density profiles determined for nighttime conditions [Thomson and McRae, 2009]. Riometer $\triangle \mathrm{CNA}$ values for the $X$ mode are calculated from the EEP flux after determining the electron number density profile as outlined in Rodger et al. [2012, section 2.4], after which riometers absorption values are calculated following the equations in Rodger et al. [2012, section 2.1].

[25] The MEPED/POES electron precipitation observations are of integral fluxes, which must be transformed into differential fluxes in order to determine ionization rates and hence the ionospheric changes. As a starting point, we consider the case of EEP with an energy spectrum provided by experimental measurements from the Detection of Electromagnetic Emissions Transmitted from Earthquake Regions (DEMETER) spacecraft [Clilverd et al., 2010], which were found to be consistent with a power law relationship. A more general examination of DEMETER electron observations also concluded that power laws were accurate representations of the flux spectrum [Whittaker et al., 2013]. While DEMETER primarily measured electrons in the DLC, its measurements are more likely to be representative of the BLC than those of the trapped electron fluxes.

\subsection{Case Study}

[26] Before examining the larger data set of overpasses, we start by presenting a case study where a single POES spacecraft passes very close to the Kilpisjärvi riometer. On 3 December 2005 at 01:54 UT, the NOAA-18 satellite passed within $\sim 0.3^{\circ}$ of the Kilpisjärvi riometer (taking into account the need to correct for fieldline tracing). At this time, the $A E$ index was $442 \mathrm{nT}$, suggesting a period of substorm activity. This is also consistent with the riometer vertical beam $\Delta \mathrm{CNA}$, which recorded $1.13 \mathrm{~dB} \pm 0.09 \mathrm{~dB}$ and the mean $/ \mathrm{me}-$ dian value of the Kilpisjärvi riometer array (excluding the corner beams) was $0.9503 \mathrm{~dB} / 0.9151 \mathrm{~dB}$, respectively. We accept MEPED/POES electron precipitation observations from NOAA-18 when it is within $\pm 3^{\circ}$ latitude of Kilpisjärvi, leading to $121 \mathrm{~s}$ samples spanning $24 \mathrm{~s}$. The EEP observations are high, also consistent with substorm activity. The mean $>30,>100$, and $>300 \mathrm{keV}$ precipitating fluxes reported were $3.54 \times 10^{6}, 2.61 \times 10^{4}$, and 514.3 electrons $\mathrm{cm}^{-2} \mathrm{~s}^{-1} \mathrm{sr}^{-1}$, while the median fluxes are $3.69 \times 10^{6}$, $2.02 \times 10^{4}$, and 514.3 electrons $\mathrm{cm}^{-2} \mathrm{~s}^{-1} \mathrm{sr}^{-1}$. Note that the median and mean are very similar to one another (the $>30 \mathrm{keV}$ values differ by only $\sim 4 \%$ ). Following the process outlined in section 4.1, we use these EEP observations to determine the changed ionospheric electron density profile and hence calculate a predicted $\triangle \mathrm{CNA}$. These are $1.09 \mathrm{~dB}$ for the mean EEP observations and $1.13 \mathrm{~dB}$ for the median EEP observations, thus highly consistent with the experimental riometer observations.

[27] This suggests that it is possible to directly relate POES EEP fluxes with riometer absorption measurements. In the following sections, we investigate this further and for a wider range of geomagnetic conditions.

\subsection{All POES Overflights}

[28] We now expand our analysis to calculate predicted $\triangle C N A$ values for all of the overflights identified in section 3 ; these are shown in Figure 6 (left). The $\triangle \mathrm{CNA}$ calculations for both mean (green stars) and median (red stars) EEP fluxes are shown, along with the experimentally observed $\triangle \mathrm{CNA}$ from the IRIS vertical riometer beam (blue squares). In this figure, we also show polynomial fits (third order) between the observed $>30 \mathrm{keV}$ EEP fluxes and the various $\triangle \mathrm{CNA}$. In general, the $\triangle \mathrm{CNA}$ calculated from the mean and median EEP fluxes are the same, with the green (mean) and red (median) fitting lines lying almost on top of one another. Uncertainties in the experimental data are calculated from the standard error using the observed variance of the $\triangle \mathrm{CNA}$ in each minute. The dashed blue lines in Figure 6 (left) show fitted lines to the experimentally observation uncertainty range. There is considerably more scatter in the experimentally observed $\triangle \mathrm{CNA}$, although there is a clear tendency for experimental riometer observations to show higher $\triangle \mathrm{CNA}$ for larger EEP fluxes, as expected. At low EEP fluxes, there is an offset between the observed and calculated $\triangle \mathrm{CNA}$, with the calculated values being 7-9 times lower than experimentally observed. This is not the case for high EEP fluxes, where there is much better agreement, and no clear evidence of a consistent offset.

[29] For a given satellite-observed $>30 \mathrm{keV}$ EEP flux, there is considerable scatter in the experimentally observed $\triangle \mathrm{CNA}$. Some of this scatter will be due to experimental uncertainty, as reflected by the dashed lines in Figure 6, caused by spatial and temporal variations between the EEP observed by the satellite at its location and that striking the ionosphere above the riometer. Analysis of a subset of riometer absorption events suggests that temporal variations over $\sim 30$ s timescales can account for the majority of the scatter observed in 

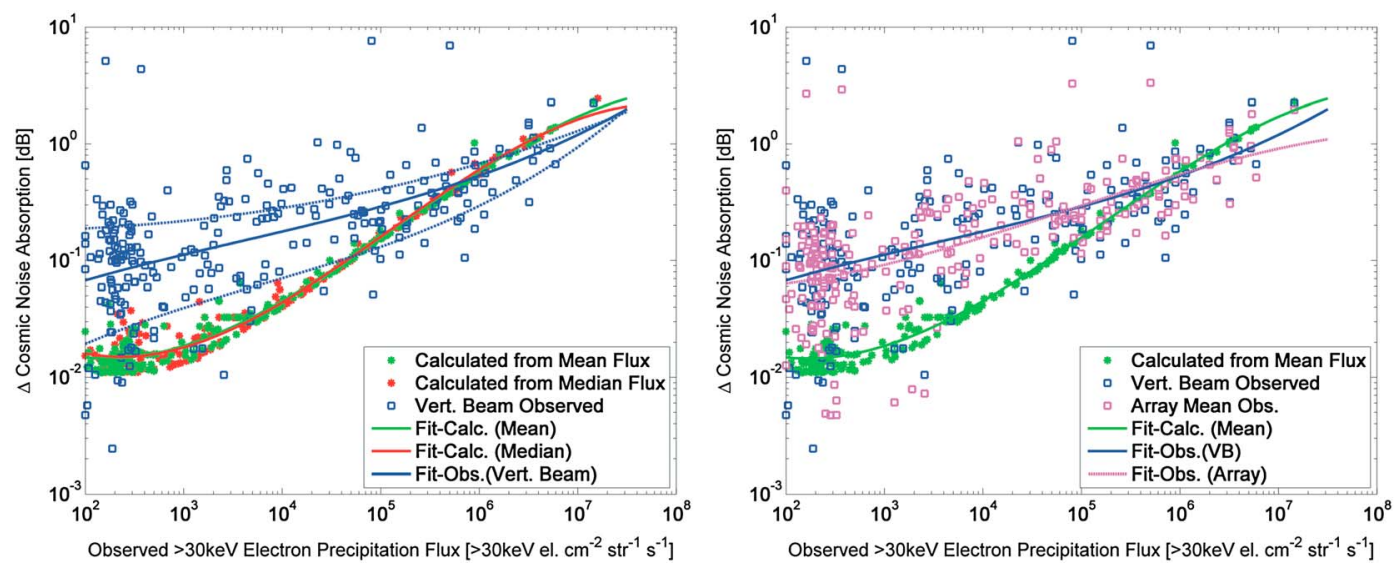

Figure 6. Comparison between the $\triangle \mathrm{CNA}$ calculated from the MEPED/POES EEP observations and those experimentally observed at Kilpisjärvi at the same times. (left) The calculations for both mean (green stars) and median (red stars). EEP flux are shown, along with the experimental $\triangle$ CNA from the IRIS vertical riometer beam (blue squares). Polynomial fits (third order) between the observed $>30 \mathrm{keV}$ EEP fluxes and the $\triangle \mathrm{CNA}$ given by the lines, while the dashed blue line shows fits to the experimental uncertainties. (right) The same form as Figure 6 (left) but includes the experimental $\Delta$ CNA from the IRIS array (magenta squares and dashed line), as well as the vertical beam.

the experimental observations. The scatter in the calculated $\triangle \mathrm{CNA}$ is caused by the different energy spectra determined for each event from the satellite data. While there is significantly more scatter in the experimental observations, there is clearly an offset between the experimental and calculated $\triangle$ CNA values.

[30] One possible explanation for the differences between the observed and calculated riometer absorptions is fine structure in the EEP, such that the vertical-directed beam is not a good representation of the typical absorption occurring across a wide field of view. In Figure 6 (right), we also plot the mean $\triangle$ CNA from across the entire Kilpisjärvi IRIS array, excluding the four corner beams (beams 1, 7, 43, and 49). Again, a polynomial best fit line is included, suggesting that typically the vertical beam is a good estimate of the average $\triangle$ CNA expected for a wide-beam case. Essentially, the same consistent offsets are seen in Figure 6. It is also not possible to explain the offsets in terms of the longitudinal distance between the spacecraft overflight and the location of Kilpisjärvi, as the calculated $\triangle \mathrm{CNA}$ are consistently high for low fluxes independent of this distance (not shown).

\subsection{Sensitivity to Electron Energy Spectrum}

[31] In the analysis above, we assumed that the EEP was described by a power law spectral gradient, following the evidence in the experimental literature. The form of the calculated $\triangle \mathrm{CNA}$ in Figure 6 is quite strongly linked to the power law fitted to the POES-observed EEP fluxes. For low $\triangle \mathrm{CNA}$ values, associated with $>30 \mathrm{keV}$ fluxes less than $10^{3} \mathrm{~cm}^{-2} \mathrm{~s}^{-1} \mathrm{sr}^{-1}$, the spectrum is very "flat" with power laws larger than -1.5 . This is to be expected as the three flux measurements are close to the $10^{2} \mathrm{~cm}^{-2} \mathrm{~s}^{-1} \mathrm{sr}^{-1}$ noise floor value for all channels. With increasing flux magnitude, the power law spectral gradient becomes increasingly negative, with values of -4 to -5 at the highest magnitudes.

[32] In order to test the sensitivity of the calculations shown in Figure 6, and in particular the offset observed, we consider some different representations for the EEP. We undertook the same analysis as described above but used an $e$-folding relationship to describe the energy spectrum. This produces (not shown) fewer valid fits (167 rather than 243) but essentially the same fitted lines seen in Figure 6 (left) (i.e., the green and blue lines).

\section{Difference Between Calculated and Observed $\triangle \mathrm{CNA}$}

\subsection{Spatial Variability of Precipitation}

[33] We have already considered that differences between the observed $\triangle \mathrm{CNA}$ and that calculated from the MEPED/ POES EEP fluxes might be due to local fine structure and established that this cannot explain the offsets. The overpass criterion is that POES must fly within $\pm 3^{\circ}$ in latitude and $\pm 10^{\circ}$ in longitude of the central location of IRIS. The IRIS field of view encompasses $2^{\circ}$ latitude and $5^{\circ}$ longitude, and consequently, there will be times when the overflights are not directly within the fields of view. It is established that $\triangle \mathrm{CNA}$ can display large variations in precipitation across several degrees of longitude; this can stem from the variability of the substorm injection region location on the nightside [e.g., Kavanagh et al., 2007], the presence of discrete but moderately energetic forms such as omega bands [Kavanagh et al., 2009], or from the presence of geomagnetic pulsations modulating the precipitation [e.g., Beharrell et al., 2010]. We have tested whether the longitudinal separation can explain the observed offsets, but there is no relationship between the two: The calculated $\triangle \mathrm{CNA}$ are consistently high for low fluxes independent of the longitudinal separation (not shown).

\subsection{Dependence Upon Geomagnetic Activity}

[34] Figure 4 showed that the EEP flux magnitude had a strong dependence upon geomagnetic storm levels, consistent with multiple previous studies [e.g., Clilverd et al., 2010; Whittaker et al., 2013]. Figure 7 (top row) show the dependence of calculated (Figure 7 (top, left)) and observed (Figure 7 (top, right)) $\triangle \mathrm{CNA}$ on geomagnetic activity, in this 

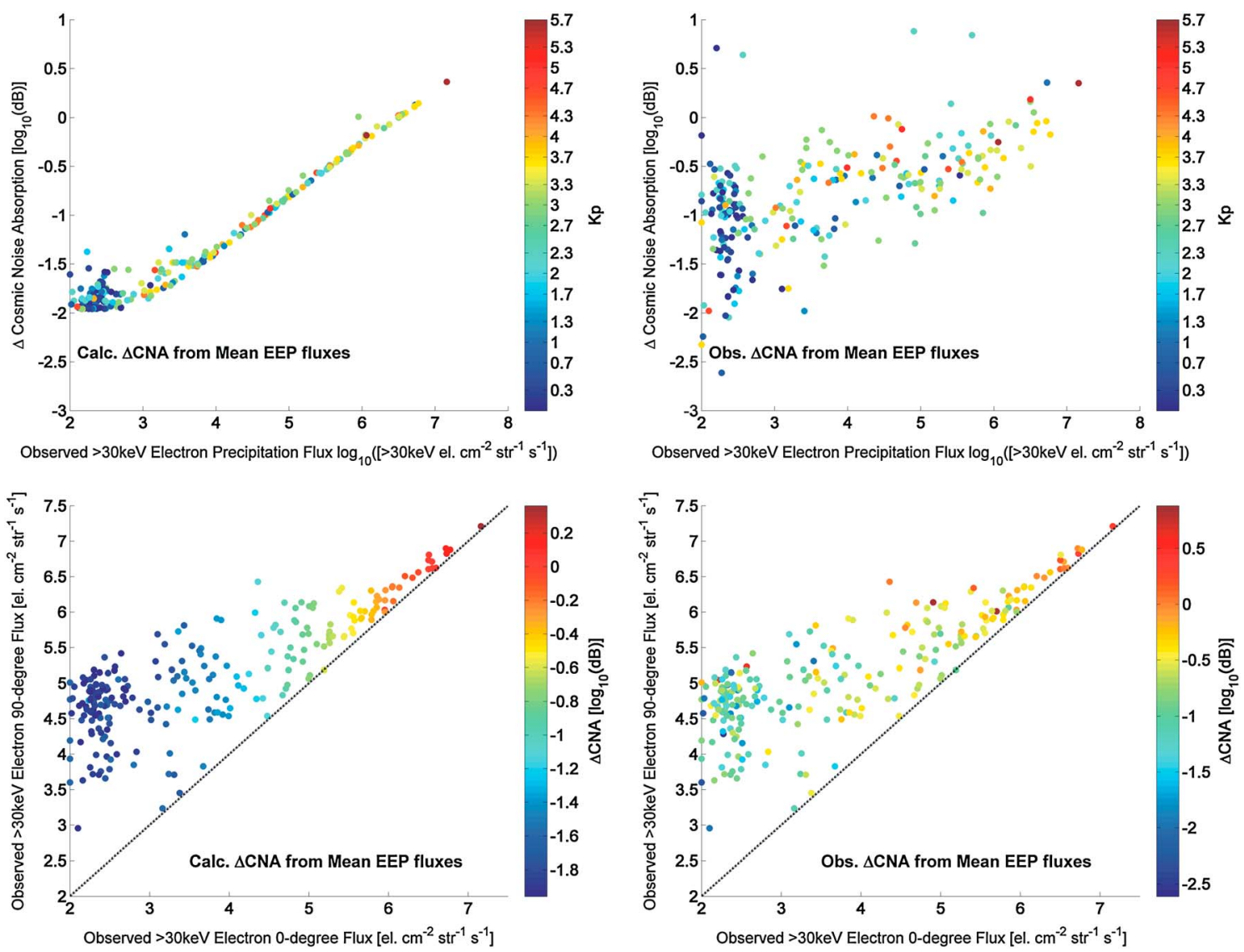

Figure 7. (top row) Examination of the dependence between the calculated (top, left) and observed (top, right) $\triangle \mathrm{CNA}$ with geomagnetic activity. The $\triangle \mathrm{CNA}$ values are taken from Figure 7 , with geomagnetic activity represented using the $K p$ index. (bottom row) Examination of the dependence on the $\Delta \mathrm{CNA}$ on the fluxes observed by the $0^{\circ}$ telescope ( $x$ axis, EEP fluxes) and the $90^{\circ}$ telescope ( $y$ axis, trapped fluxes). Here (bottom, left) $\triangle \mathrm{CNA}$ calculated from mean EEP fluxes and (bottom, right) observed $\triangle \mathrm{CNA}$ are shown.

case through $K p$. Both the calculated $\triangle \mathrm{CNA}$ (taken from POES EEP observations) and the observed $\triangle \mathrm{CNA}$ show a general organization depending on $K p$; very small $\Delta \mathrm{CNA}$ occurs at geomagnetically very quiet times $(K p<2)$, while larger $\triangle \mathrm{CNA}$ occur during more disturbed conditions. There is not a one-to-one relationship between the $\triangle \mathrm{CNA}$ and $K p$, which may indicate that the EEP flux levels vary strongly on short timescales (i.e., from minute to minute) when contrasted with the $3 \mathrm{~h}$ resolution of the $K p$ parameter. Nonetheless, there is a broad organization of the $\triangle \mathrm{CNA}$ with $K p$ (and to a weaker extent, $A E$ (not shown)). This is somewhat consistent with previous studies [e.g., Kavanagh et al., 2004a] that have shown an organization with $K p$ but with a large spread of absorption values.

\subsection{Dependence Upon Weak/Strong Diffusion}

[35] Figure 6 suggests that there is a significant disagreement between the POES-predicted $\triangle \mathrm{CNA}$ and that observed, but only for smaller EEP fluxes, less than about $10^{5}-10^{6} \mathrm{~cm}^{-2}$ $\mathrm{s}^{-1} \mathrm{sr}^{-1}$ for $>30 \mathrm{keV}$ electrons. This issue is very likely to occur during quiet geomagnetic conditions or weaker geomagnetic disturbances (as seen in Figure 7 (top row)). One possible reason for the POES-predicted $\triangle \mathrm{CNA}$ being lower than that observed is simply that the MEPED/POES $0^{\circ}$ directed telescope fails to measure the EEP occurring in these cases. As noted in section 2.2, EEP may occur for pitch angles near the edges of the BLC but be missed by the $0^{\circ}$ directed telescope. This is more likely when weak diffusion is occurring, that is when the pitch angle scattering processes involve small changes in pitch angle, and the peak fluxes are close to the edge of the BLC. Our suggestion is consistent for quiet and weakly disturbed geomagnetic conditions when weak diffusion is expected to be more observable. During strong disturbances, we expect strong diffusion to dominate. We consider that weak diffusion could be a factor in the observed offsets during these periods of low geomagnetic activity. We test this idea in Figure 7 (bottom row), which show the mean EEP $>30 \mathrm{keV}$ fluxes reported over Kilpisjärvi in the $0^{\circ}$ and $90^{\circ} \mathrm{di}-$ rected telescopes. The $90^{\circ}$ telescope largely observes electrons which are stably trapped [Rodger et al., 2010b] but are mirroring at POES satellite altitudes and thus have equatorial pitch angles which are not much above the DLC or BLC angles. During weak diffusion pitch angle scattering, one would expect large differences between the fluxes of the $0^{\circ}$ and $90^{\circ}$ telescopes. However, during strong diffusion, electrons will be pitch angle scattered from high pitch angles toward the BLC and will pass through the pitch angle range of the $90^{\circ}$ telescope on the way to the pitch angle range of the $0^{\circ}$ telescope (and hence being lost). While the pitch angles measured by the $90^{\circ}$ telescope are trapped fluxes, for strong diffusion 

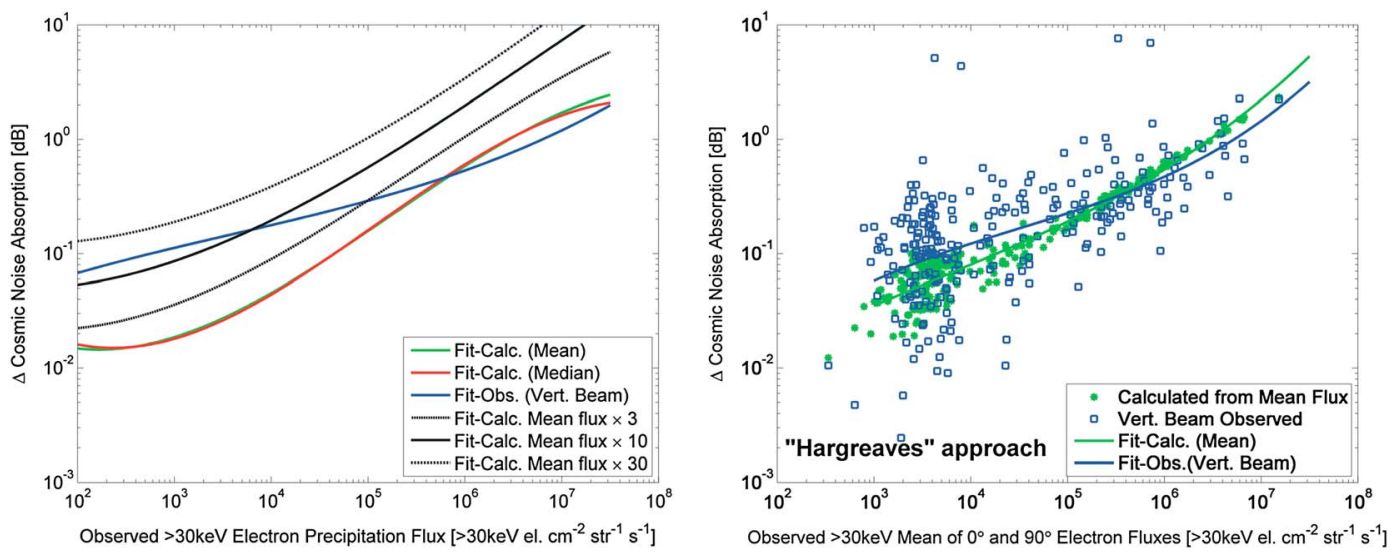

Figure 8. (left) Examining the significance of the "missing" MEPED/POES EEP fluxes. The green, red, and blue lines show the polynomial fits taken from Figure 7 for the $\triangle$ CNA calculated from the MEPED/ POES EEP mean and median flux and the observed $\triangle \mathrm{CNA}$, respectively. The black lines show the fits for $\triangle$ CNA calculated from linearly boosted MEPED/POES mean EEP fluxes. (right) Comparison between the $\triangle$ CNA observed and that calculated from the geometric mean of fluxes reported by the $0^{\circ}$ and $90^{\circ}$ telescopes (termed the "Hargreaves approach").

processes those electrons rapidly move to lower pitch angles and thus precipitate into the atmosphere.

[36] We use colored dots in Figure 7 (bottom row) to show the riometer $\triangle \mathrm{CNA}$ and how it relates to the MEPED/POES observed fluxes. Figure 7 (bottom, left) shows the $\triangle \mathrm{CNA}$ calculated from mean EEP fluxes while Figure 7 (bottom, right) shows the observed $\triangle \mathrm{CNA}$ at Kilpisjärvi. When the EEP fluxes are low and the $\triangle \mathrm{CNA}$ is small, there is $\sim 2$ orders of magnitude difference between the $0^{\circ}$ telescope and $90^{\circ}$ telescope fluxes, consistent with weak diffusion. In contrast, when the $\triangle \mathrm{CNA}$ is large $(\sim 0.5-0.6 \mathrm{~dB})$, the $90^{\circ}$ telescope fluxes are only $20-50 \%$ larger than those reported by the $0^{\circ}$ telescope, suggesting strong diffusion is taking place. This would appear to explain why the POES-predicted $\triangle \mathrm{CNA}$ are in reasonable agreement with observations for high EEP fluxes, as the BLC will be full, and the pitch angle range viewed by the $0^{\circ}$ telescope will provide a good approximation for the BLC fluxes.

[37] We now test the extent to which the MEPED/POES observed fluxes underestimate the "true flux" in the BLC. Figure 8 (left) shows the polynomial fits for the observed $\triangle \mathrm{CNA}$ at Kilpisjärvi (blue line) and that calculated from the mean and median POES EEP fluxes (green and red lines, respectively) taken from Figure 6 . The black lines in this figure show the $\triangle$ CNA calculated from the Mean POES EEP fluxes boosted by 3,10 , and 30 times. For POES $>30 \mathrm{keV}$ EEP fluxes below $10^{4} \mathrm{~cm}^{-2} \mathrm{~s}^{-1} \mathrm{sr}^{-1}$, the satellite-reported fluxes need to be increased by $\sim 10-15$ times in order to reproduce the observed $\triangle \mathrm{CNA}$. For satellite fluxes $\sim 10^{5} \mathrm{~cm}^{-2} \mathrm{~s}^{-1} \mathrm{sr}^{-1}$, the POES $0^{\circ}$ telescope appears to be observing only about one third of the precipitating fluxes, while the agreement becomes better as strong diffusion becomes more significant at higher fluxes.

\section{Discussion}

[38] Hargreaves et al. [2010] also contrasted MEPED/ POES electron flux observations with observations made by the Kilpisjärvi riometer for 10 overpasses, albeit using SEM-2 data. They assumed that the square of the absorption (in decibels) should be proportional to the precipitating flux and undertook a series of case studies as the satellites flew over the riometer. This study also reported that the $0^{\circ}$ telescope precipitating fluxes tended to underestimate the riometer absorption and suggested that the true BLC fluxes might be better represented by combining observations from the two telescopes. Hargreaves et al. [2010] did not find that the predicted and observed absorptions agreed only for high fluxes but were limited to only four higher flux nighttime events.

[39] For our identified passes, we take the same approach, combining the POES $0^{\circ}$ and $90^{\circ}$ telescope data and taking the geometric mean; we will call this the "Hargreaves" approach. We then calculate the $\triangle \mathrm{CNA}$ using the technique outlined in section 4.3 (i.e., assuming a power law spectral gradient and fitting the mean flux data for each channel with this). Figure 8 (right) shows the results of this comparison, using the same format as Figure 6. In this case there were 252 valid fits, and the agreement at low $>30 \mathrm{keV}$ EEP flux magnitudes is considerably better. It appears that the Hargreaves approach leads to the MEPED/POES precipitating fluxes which are on average too high in lower ranges $\left(<10^{5} \mathrm{~cm}^{-2} \mathrm{~s}^{-1} \mathrm{sr}^{-1}\right)$. A comparison between Figure 8 (left) and Figure 8 (right) suggests the overestimate of flux is less than $\sim 2$ times, which is clearly more accurate than the 10-15 times offset we found when considering only the $0^{\circ}$ telescope observations. This approach also overcomes the problem "missing" fluxes in the $0^{\circ}$ telescope for weak diffusion and low geomagnetic activity periods by gaining additional information from the $90^{\circ}$ telescope.

[40] The Hargreaves approach relies on the $90^{\circ}$ telescope observing electrons which are close to the loss cone. It is perhaps not surprising that the geometric mean of the $0^{\circ}$ and $90^{\circ}$ telescope observations overestimate the precipitating fluxes, as the $90^{\circ}$ telescope generally measures trapped electrons, the flux of which are much larger than those being lost. Nonetheless, the combination of the two look directions clearly leads to better quality EEP estimates. We suggest follow on work needs to be undertaken to test if this holds for other longitudes and geomagnetic latitudes. 


\section{Summary and Conclusions}

[41] MEPED/POES energetic electron precipitation (EEP) measurements are widely used to describe the impact of the EEP upon the middle atmosphere and/or lower ionosphere. In this paper we examined MEPED/POES EEP measurements during satellite overflights of a riometer located in Kilpisjärvi, Finland, so as to test the validity of the satellite EEP measurements. We find that the $0^{\circ}$ telescope tends to underreport the magnitude of EEP occurring when the $>30 \mathrm{keV}$ flux magnitude is lower than about $10^{6} \mathrm{~cm}^{-2} \mathrm{~s}^{-1} \mathrm{sr}^{-1}$. The missing flux levels can be very significant, as much as $10-15$ times less flux is present in the satellite observations than is observed striking the ionospheric $D$ region using ground-based measurements. In contrast, for $>30 \mathrm{keV}$ flux magnitudes $>10^{6} \mathrm{~cm}^{-2} \mathrm{~s}^{-1} \mathrm{sr}^{-1}$, there is comparatively good agreement between the satellite EEP flux and the ground-based measurements. The discrepancy between the satellite EEP and riometer observations are most pronounced for low geomagnetic disturbance conditions. At these times, the EEP magnitudes are low, and weak diffusion dominates the pitch angle scattering processes which drive the electrons into the atmosphere. Again, in contrast, the agreement is best during disturbed geomagnetic conditions, when strong diffusion is taking place.

[42] These observations can be explained due to the size and orientation of the MEPED/POES $0^{\circ}$ telescope inside the bounce loss cone (BLC). As the $0^{\circ}$ telescope views only part of the inside of the BLC pitch angle range, EEP into the atmosphere may take place with a large fraction of the precipitating electrons outside the $0^{\circ}$ telescope pitch angle range. This will be most significant for weak diffusion conditions, when the pitch angle scattering processes will tend to push electrons over the edge of the BLC boundary but not deep into the BLC. However, for strong diffusion conditions, there will be more flux in the BLC, and we find that the $0^{\circ}$ telescope provides a good estimate of the total precipitating flux.

[43] We have also considered a suggestion from an earlier case study, that the combination of observations from the $0^{\circ}$ and $90^{\circ}$ telescopes provide a more accurate measure of the "true" EEP fluxes into the atmosphere [Hargreaves et al., 2010]. We confirm that the geometric mean flux from the two telescopes produces calculated riometer absorptions which are typically more like those observed than found when using only the $0^{\circ}$ telescope. The application of this suggestion needs to be tested for a wider range of locations. However, we note that it provides great promise, being a comparatively easy technique to improve the quality of EEP observations.

[44] We have shown that care needs to be taken when using MEPED/POES $0^{\circ}$ EEP fluxes. Strong scattering processes fill the BLC with relatively uniform pitch angle distributions, while weak scattering processes result in nonuniform distributions. These distributions result in a gradual adjustment factor of $\sim 10-15$ for low fluxes to $\sim 1-3$ for high fluxes.

[45] Acknowledgments. C.J.R. was supported by the New Zealand Marsden Fund. M.A.C. was supported by the Natural Environmental Research Council grant NE/J008125/1. The authors would like to thank the researchers and engineers of NOAA's Space Environment Center for the provision of the data and the operation of the SEM-2 instrument carried onboard these spacecraft. The riometer data originated from the Imaging Riometer for Ionospheric Studies (IRIS), operated by the Space Plasma Environment and Radio Science (SPEARS) group, Department of Physics, Lancaster University (UK) in collaboration with the Sodankylä Geophysical Observatory.

[46] Masaki Fujimoto thanks Donat Blagoveshchensky and Martin Friedrich for their assistance in evaluating this paper.

\section{References}

Andersson, M. E., P. T. Verronen, S. Wang, C. J. Rodger, M. A. Clilverd, and B. R. Carson (2012), Precipitating radiation belt electrons and enhancements of mesospheric hydroxyl during 2004-2009, J. Geophys. Res., 117, D09304, doi:10.1029/2011JD017246.

Andersson, M., P. T. Verronen, C. J. Rodger, M. A. Clilverd, and S. Wang (2013), Longitudinal hot-spots in the mesospheric OH variations due to energetic electron precipitation, Atmos. Chem. Phys. Discuss., 13, 19,895-19,919.

Baker, D. N., P. Stauning, E. W. Hones Jr., P. R. Higbie, and R. D. Belian (1979), Strong electron pitch angle diffusion observed at geostationary orbit, Geophys. Res. Lett., 6, 205-208, doi:10.1029/GL006i003p00205.

Baumgaertner, A. J. G., A. Seppälä, P. Joeckel, and M. A. Clilverd (2011), Geomagnetic activity related $\mathrm{NO}_{x}$ enhancements and polar surface air temperature variability in a chemistry climate model: Modulation of the NAM index, Atmos. Chem. Phys., 11(9), 4521-4531, doi:10.5194/acp11-4521-2011.

Beharrell, M., A. J. Kavanagh, and F. Honary (2010), On the origin of high m magnetospheric waves, J. Geophys. Res., 115, A02201, doi:10.1029/ 2009JA014709.

Brasseur, G., and S. Solomon (2005), Aeronomy of the Middle Atmosphere, 3rd ed., D. Reidel Company, Dordrecht, Netherlands.

Browne, S., J. K. Hargreaves, and B. Honary (1995), An imaging riometer for ionospheric studies, Electron. Commun. Eng. J., 7, 209-217.

Clilverd, M. A., A. Seppälä, C. J. Rodger, N. R. Thomson, P. T. Verronen, E. Turunen, T. Ulich, J. Lichtenberger, and P. Steinbach (2006), Modeling polar ionospheric effects during the October-November 2003 solar proton events, Radio Sci., 41, RS2001, doi:10.1029/2005RS003290.

Clilverd, M. A., et al. (2008), Energetic electron precipitation during substorm injection events: High latitude fluxes and an unexpected midlatitude signature, J. Geophys. Res., 113, A10311, doi:10.1029/2008JA013220.

Clilverd, M. A., C. J. Rodger, R. J. Gamble, T. Ulich, T. Raita, A. Seppälä, J. C. Green, N. R. Thomson, J.-A. Sauvaud, and M. Parrot (2010), Ground-based estimates of outer radiation belt energetic electron precipitation fluxes into the atmosphere, J. Geophys. Res., 115, A12304, doi:10.1029/2010JA015638.

Clilverd, M. A., C. J. Rodger, D. Danskin, M. E. Usanova, T. Raita, T. Ulich, and E. L. Spanswick (2012), Energetic particle injection, acceleration, and loss during the geomagnetic disturbances which upset Galaxy 15, J. Geophys. Res., 117, A12213, doi:10.1029/2012JA018175.

Clilverd, M. A., N. Cobbett, C. J. Rodger, J. B. Brundell, M. Denton, D. Hartley, J. Rodriguez, D. Danskin, T. Raita, and E. L. Spanswick (2013), Energetic electron precipitation characteristics observed from Antarctica during a flux dropout event, J. Geophys. Res. Space Physics, 118, 1-15, doi:10.1002/2013JA019067.

Collis, P. N., J. K. Hargreaves, and A. Korth (1984), Auroral radio absorption as an indicator of magnetospheric electrons and of conditions in the disturbed auroral D-region, J. Atmos. Terr. Phys., 46, 21-38, doi:10.1016/0021-9169(84)90041-2.

Daae, M., P. Espy, H. Nesse Tyssøy, D. Newnham, J. Stadsnes, and F. Søraas (2012), The effect of energetic electron precipitation on middle mesospheric night-time ozone during and after a moderate geomagnetic storm, Geophys. Res. Lett., 39, L21811, doi:10.1029/2012GL053787.

Detrick, D. L., and T. J. Rosenberg (1990), A phased-array radiowave imager for studies of cosmic noise absorption, Radio Sci., 25, 325-338.

Dietrich, S., C. J. Rodger, M. A. Clilverd, J. Bortnik, and T. Raita (2010), Relativistic microburst storm characteristics: Combined satellite and ground-based observations, J. Geophys. Res., 115, A12240, doi:10.1029/ 2010JA015777.

Evans, D. S., and M. S. Greer (2004), Polar orbiting environmental satellite space environment monitor - 2 instrument descriptions and archive data documentation, NOAA technical Memorandum version 1.4, Space Environment Laboratory, Colorado.

Funke, B., et al. (2011), Composition changes after the "Halloween" solar proton event: The High Energy Particle Precipitation in the Atmosphere (HEPPA) model versus MIPAS data intercomparison study, Atmos. Chem. Phys., 11, 9089-9139, doi:10.5194/acp-11-9089-2011.

Gamble, R. J., C. J. Rodger, M. A. Clilverd, J.-A. Sauvaud, N. R. Thomson, S. L. Stewart, R. J. McCormick, M. Parrot, and J.-J. Berthelier (2008), Radiation belt electron precipitation by man-made VLF transmissions, J. Geophys. Res., 113, A10211, doi:10.1029/2008JA013369.

Green, J. C., T. G. Onsager, T. P. O'Brien, and D. N. Baker (2004), Testing loss mechanisms capable of rapidly depleting relativistic electron flux in the Earth's outer radiation belt, J. Geophys. Res., 109, A12211, doi:10.1029/2004JA010579.

Hargreaves, J. K., M. J. Birch, and D. S. Evans (2010), On the fine structure of medium energy electron fluxes in the auroral zone and related effects in the ionospheric D-region, Ann. Geophys., 28, 1107-1120, doi:10.5194/ angeo-28-1107-2010. 
Hendry, A. T., C. J. Rodger, M. A. Clilverd, N. R. Thomson, S. K. Morley, and T. Raita (2013), Rapid radiation belt losses occurring during high-speed solar wind stream-driven storms: Importance of energetic electron precipitation, in Dynamics of the Earth's Radiation Belts and Inner Magnetosphere, Geophys. Monogr. Ser., vol. 199, edited by D. Summers et al., 213-223, AGU, Washington, D. C., doi:10.1029/2012GM001299.

Horne, R. B., M. M. Lam, and J. C. Green (2009), Energetic electron precipitation from the outer radiation belt during geomagnetic storms, Geophys. Res. Lett., 36, L19104, doi:10.1029/2009GL040236.

Kavanagh, A. J., M. J. Kosch, F. Honary, A. Senior, S. R. Marple, E. E. Woodfield, and I. W. McCrea (2004a), The statistical dependence of auroral absorption on geomagnetic and solar wind parameters, Ann. Geophys., 22, 877-887, doi:10.5194/angeo-22-877-2004.

Kavanagh, A. J., S. R. Marple, F. Honary, I. W. McCrea, and A. Senior (2004b), On solar protons and polar cap absorption: Constraints on an empirical relationship, Ann. Geophys., 22, 1133-1147, doi:10.5194/ angeo-22-1133-2004.

Kavanagh, A. J., G. Lu, E. F. Donovan, G. D. Reeves, F. Honary, J. Manninen, and T. J. Immel (2007), Energetic electron precipitation during sawtooth injections, Ann. Geophys., 25, 1199-1214, doi:10.5194/ angeo-25-1199-2007.

Kavanagh, A. J., J. A. Wild, and F. Honary (2009), Observations of omega bands using an imaging riometer, Ann. Geophys., 27, 4183-4195, doi:10.5194/angeo-27-4183-2009.

Kavanagh, A. J., F. Honary, E. F. Donovan, T. Ulich, and M. H. Denton (2012), Key features of $>30 \mathrm{keV}$ electron precipitation during high speed solar wind streams: A superposed epoch analysis, J. Geophys. Res., 117, A00L09, doi:10.1029/2011JA017320.

Kennel, C. F., and H. E. Petschek (1966), Limit on stably trapped particle fluxes, J. Geophys. Res., 71, 1-28.

Lam, M. M., R. B. Horne, N. P. Meredith, S. A. Glauert, T. Moffat-Griffin, and J. C. Green (2010), Origin of energetic electron precipitation $>30 \mathrm{keV}$ into the atmosphere, J. Geophys. Res., 115, A00F08, doi:10.1029/ 2009JA014619.

Little, C. G., and H. Leinbach (1959), The riometer -A device for the continuous measurement of ionospheric absorption, Proc. IRE, 47, 315-319.

Millan, R. M., and R. M. Thorne (2007), Review of radiation belt relativistic electron loss, J. Atmos. Sol. Terr. Phys., 69, 362-377, doi:10.1016/ j.jastp.2006.06.019.

Neal, J. J., C. J. Rodger, and J. C. Green (2013), Empirical determination of solar proton access to the atmosphere: Impact on polar flight paths, Space Weather, 420-433, doi:10.1002/swe.2006.

Newnham, D. A., P. J. Espy, M. A. Clilverd, C. J. Rodger, A. Seppälä, D. J. Maxfield, P. Hartogh, K. Holmén, and R. B. Horne (2011), Direct observations of nitric oxide produced by energetic electron precipitation in the Antarctic middle atmosphere, Geophys. Res. Lett., 38, L20104, doi:10.1029/2011GL049199.

Reeves, G. D., K. L. McAdams, R. H. W. Friedel, and T. P. O'Brien (2003), Acceleration and loss of relativistic electrons during geomagnetic storms, Geophys. Res. Lett., 30(10), 1529, doi:10.1029/2002GL016513.

Robel, J. (Ed.) (2009), NOAA KLM User's guide, National Environmental Satellite, Data, and Information Service.

Rodger, C. J., M. A. Clilverd, N. R. Thomson, R. J. Gamble, A. Seppälä, E. Turunen, N. P. Meredith, M. Parrot, J.-A. Sauvaud, and J.-J. Berthelier (2007), Radiation belt electron precipitation into the atmosphere: Recovery from a geomagnetic storm, J. Geophys. Res., 112, A11307, doi:10.1029/ 2007JA012383.

Rodger, C. J., M. A. Clilverd, J. Green, and M.-M. Lam (2010a), Use of POES SEM-2 observations to examine radiation belt dynamics and energetic electron precipitation in to the atmosphere, J. Geophys. Res., 115, A04202, doi:10.1029/2008JA014023.

Rodger, C. J., B. R. Carson, S. A. Cummer, R. J. Gamble, M. A. Clilverd, J. C. Green, J.-A. Sauvaud, M. Parrot, and J. J. Berthelier (2010b) Contrasting the efficiency of radiation belt losses caused by ducted and nonducted whistler-mode waves from ground-based transmitters, J. Geophys. Res., 115, A12208, doi:10.1029/2010JA015880.
Rodger, C. J., M. A. Clilverd, A. Seppälä, N. R. Thomson, R. J. Gamble, M. Parrot, J. A. Sauvaud, and Th Ulich (2010c), Radiation belt electron precipitation due to geomagnetic storms: Significance to middle atmosphere ozone chemistry, J. Geophys. Res., 115, A11320, doi:10.1029/ 2010JA015599.

Rodger, C. J., M. A. Clilverd, A. J. Kavanagh, C. E. J. Watt, P. T. Verronen, and T. Raita (2012), Contrasting the responses of three different groundbased instruments to energetic electron precipitation, Radio Sci., 47, RS2021, doi:10.1029/2011RS004971.

Rozanov, E., L. Callis, M. Schlesinger, F. Yang, N. Andronova, and V. Zubov (2005), Atmospheric response to NOy source due to energetic electron precipitation, Geophys. Res. Lett., 32, L14811, doi:10.1029/ 2005GL023041.

Seppälä, A., P. T. Verronen, V. F. Sofieva, J. Tamminen, E. Kyrölä, C. J. Rodger, and M. A. Clilverd (2006), Destruction of the tertiary ozone maximum during a solar proton event, Geophys. Res. Lett., 33, L07804, doi:10.1029/2005GL025571.

Seppälä, A., M. A. Clilverd, and C. J. Rodger (2007), NOx enhancements in the middle atmosphere during 2003-2004 polar winter: Relative significance of solar proton events and the aurora as a source, J. Geophys. Res., 112, D23303, doi:10.1029/2006JD008326.

Seppälä, A., C. E. Randall, M. A. Clilverd, E. Rozanov, and C. J. Rodger (2009), Geomagnetic activity and polar surface level air temperature variability, J. Geophys. Res., 114, A10312, doi:10.1029/2008JA014029.

Seppälä, A., H. Lu, M. A. Clilverd, and C. J. Rodger (2013), Geomagnetic activity signatures in wintertime stratosphere-troposphere temperature, wind, and wave response, J. Geophys. Res. Atmos., 118, 2169-2183, doi: $10.1002 /$ jgrd.50236

Spjeldvik, W. N., and P. L. Rothwell (1985), The radiation belts, in Handbook of Geophysics and the Space Environment, edited by A. S. Jursa, pp. 5-1-5-55, Air Force Geophys. Lab., Springfield, Va.

Thomson, N. R., and W. M. McRae (2009), Nighttime ionospheric D region: Equatorial and nonequatorial, J. Geophys. Res., 114, A08305, doi:10.1029/2008JA014001.

Turunen, E., P. T. Verronen, A. Seppälä, C. J. Rodger, M. A. Clilverd, J. Tamminen, C. F. Enell, and T. Ulich (2009), Impact of different energies of precipitating particles on $\mathrm{NO}_{x}$ generation in the middle and upper atmosphere during geomagnetic storms, J. Atmos. Sol. Terr. Phys., 71 , 1176-1189, doi:10.1016/j.jastp.2008.07.005.

Verronen, P. T., C. J. Rodger, M. A. Clilverd, and S. Wang (2011), First evidence of mesospheric hydroxyl response to electron precipitation from the radiation belts, J. Geophys. Res., 116, D07307, doi:10.1029/ 2010JD014965.

Walt, M. (1984), Introduction to Geomagnetically Trapped Radiation, Cambridge Univ. Press, Cambridge, U. K.

Whittaker, I. C., R. J. Gamble, C. J. Rodger, M. A. Clilverd, and J. A. Sauvaud (2013), Determining the spectra of radiation belt electron losses: Fitting DEMETER IDP observations for typical and storm-times, J. Geophys. Res. Space Pysics, doi:10.1002/2013JA019228, in press.

Wild, P., F. Honary, A. J. Kavanagh, and A. Senior (2010), Triangulating the height of cosmic noise absorption: A method for estimating the characteristic energy of precipitating electrons, J. Geophys. Res., 115, A12326, doi:10.1029/2010JA015766.

Wissing, J. M., and M.-B. Kallenrode (2009), Atmospheric Ionization module osnabrück (AIMOS): A 3-D model to determine atmospheric ionization by energetic charged particles from different populations, J. Geophys. Res., 114, A06104, doi:10.1029/2008JA013884.

Wissing, J. M., M.-B. Kallenrode, J. Kieser, H. Schmidt, M. T. Rietveld, A. Strømme, and P. J. Erickson (2011), Atmospheric Ionization Module Osnabrück (AIMOS): 3. Comparison of electron density simulations by AIMOS-HAMMONIA and incoherent scatter radar measurements, J. Geophys. Res., 116, A08305, doi:10.1029/2010JA016300.

Yando, K., R. M. Millan, J. C. Green, and D. S. Evans (2011), A Monte Carlo simulation of the NOAA POES medium energy proton and electron detector instrument, J. Geophys. Res., 116, A10231, doi:10.1029/ 2011JA016671. 